\title{
Global public health significances, healthcare perceptions of communities, treatments, prevention and control methods of COVID-19
}

\author{
Addis Adera Gebru ${ }^{\mathrm{j}, 1, \mathrm{~m}, *}$, Tadesse Birhanu ${ }^{\mathrm{b}}$, Eshetu Wendimu ${ }^{\mathrm{c}}$, Agumas Fentahun Ayalew $^{\mathrm{n}}$, \\ Selamawit Mulat ${ }^{\mathrm{d}}$, Hussen Zakir Abasimel ${ }^{\mathrm{e}}$, Ali Kazemi ${ }^{\mathrm{f}}$, Bosenu Abera Tadesse ${ }^{\mathrm{g}}$, \\ Beniam Adera Gebru ${ }^{\mathrm{h}}$, Berhanu Senbeta Deriba ${ }^{\mathrm{a}}$, Nigus Shimelis Zeleke ${ }^{\mathrm{i}}$, Abebe Gule Girma ${ }^{\mathrm{b}}$, \\ Bulgantsetseg Munkhbat ${ }^{\mathrm{b}}$, Qamar Kassim Yusuf ${ }^{\mathrm{k}}$, Amana Ogeto Luke ${ }^{\mathrm{l}}$ and Dejene Hailu ${ }^{\mathrm{o}}$ \\ ${ }^{a}$ Department of Public Health, College of Health Sciences, Salale University, Fitche, Ethiopia \\ ${ }^{\mathrm{b}}$ Department of Animal Sciences (Specialist on Infectious Diseases), College of Agriculture and Natural Resources, \\ Salale University, Fitche, Ethiopia \\ ${ }^{\mathrm{c}}$ Research and Community Services Vice President, Salale University, Fitche, Ethiopia \\ dinjibara Woreda Health Office, Regulatory Officer, Injibara, Ethiopia \\ ${ }^{\mathrm{e}}$ Department of Midwifery, College of Health Sciences, Salale University, Fitche, Ethiopia \\ ${ }_{\mathrm{f}}^{\mathrm{f}}$ Department of Health Economics, School of Public Health, Research Center for Environmental Determinants of \\ Health, Kermanshah University of Medical Sciences, Kermanshah, Iran \\ ${ }^{\mathrm{g}}$ Department of Animal Sciences, College of Agriculture and Natural Resources, Salale University, Fitche, Ethiopia \\ ${ }^{\mathrm{h}}$ Addis Ababa City Administration Public Procurement and Materials, Addis Ababa, Ethiopia \\ ${ }^{i}$ Department of Sociology, College of Social Sciences and Humanities, Salale University, Fitche, Ethiopia \\ ${ }^{\mathrm{j}}$ International Relation Directorate Director, Salale University, Fitche, Ethiopia \\ ${ }^{\mathrm{k}}$ Northern Counties Community Empowerment, Garissa, Kenya \\ ${ }^{1}$ Department of Public Health, Reft Valley University, College of Health Sciences, Abichu Campus, Addis Ababa, \\ Ethiopia \\ ${ }^{\mathrm{m}}$ Department of Public Health, College of Health Sciences, Kotebe Metropolitan University, Addis Ababa, Ethiopia \\ ${ }^{\mathrm{n}}$ Department of Public Health, College of Health Sciences, Woldia University, Woldia, Ethiopia \\ ${ }^{\circ}$ Department of Nursing, College of Health Sciences, Salale University, Fitche, Ethiopia
}

\begin{abstract}
.
BACKGROUND: The Novel Coronavirus Disease 2019 (COVID-19) has proved to be one of the most burdensome respiratory disease outbreaks ever. Moreover, the public health emergency of the COVID-19 outbreak has been seen by the World Health Organization (WHO) as global health concern since March 2020 and there has been a significantly increased morbidity and mortality in the community worldwide. The objective of this review is to describe and review the global public health significances and community and healthcare perception of features, treatments, prevention and control methods to slow the transmission of the outbreak.

METHODS: For this review, the literature has been searched by following online databases, including medRxiv, pubmed, medline and Google scholar databases. The key search terms 'COVID-19', '2019 novel coronavirus', '2019-nCoV', 'novel coronavirus' and 'Pneumonia' were used to search the literature. Scientific papers published online by the Center for Disease Control (CDC) and the WHO from 01 January to 06 May 2020 in the English language were included for analysis.
\end{abstract}

\footnotetext{
* Corresponding author: Addis Adera Gebru, Directorate of Director for International Relation and partnership, Department of Public Health, College of Health Sciences, Salale University, Fitche, Salale,
}

Ethiopia. Tel.: +251984811393; E-mail: addisaderagebru@ gmail com; addis_adera@slu.edu.et; international_relation@slu.edu.et. 
RESULTS: The results of this review indicated that COVID-19 is a serious global public health problem. It affects immune compromised individuals living with chronic diseases, the elderly and pregnant women more severely. The disease spread rapidly from one country to countries worldwide. In all, 212 countries highlighted the weakened state of essential public health and emergency services. The researchers addressed the lack of perception in communities, including health professionals, with regard to COVID-19. Healthcare settings were analyzed in terms of the pandemic nature of the virus, onset and the overall characteristics of disease outbreak. Microbiogists were also used to assess the daily cumulative index of COVID-19. With regard to treatment, chloroquine phosphate and herbal medicines were shown to be promising as supportive treatments to slow COVID-19 transmission, coupled with isolation and quarantine techniques.

CONCLUSION: The review indicates that COVID-19 has a high global public health significance due to its high morbidity and mortality rates. Still, there was no specific or effective vaccine or treatment, moreover, the community, including health professionals, have a low perception as regards COVID-19, even though different prevention and control methods have been conducted. Thus, there is a need for awareness creation, alongside further research applied to finding effective vaccine and treatments.

Keywords: Coronavirus Disease 2019, Perception, Prevention and Control, Public Health Significances, Treatments

\section{Introduction}

The Novel Coronavirus Disease 2019 (COVID-19) is one of the most burdensome respiratory disease outbreaks ever. It can affect any age, sex, group or race, however, it affects immune- compromised individuals living with chronic diseases, the elderly and pregnant women more severely. The disease has spread rapidly from one country to countries across the world. Hence, a global public health emergency to fight the COVID-19 outbreak was announced by the WHO in March [1].

An emerging novel pathogen which has significantly threatened the life of the global community since 1 January 2020, the origin of the virus is still unknown, but there is speculation that it has an animal origin $[1,2]$. As a result, it poses public health, economic, psychological resilience and social crises for all countries.

Fever, dry cough, shortness of breath (dyspnea) and tiredness are found to be the signs and symptoms of COVID-19. It's incubation period falls within 2 14 days after exposure, however, asymptomatic patients showing no clinical signs were found in Wuhan, China [3]. There are concerns about the diagnosis of COVID-19, as there is no sensitive, specific and rapid diagnostic methods to detect this virus, although reverse-transcriptase Polymerase Chain Reaction (RTPCR) and immunofluorescence antigen detection assays are currently being used to test nasopharyngeal samples [1,2].

Several researchers from different countries are struggling to develop specific and effective vaccines and treatments for COVID-19. For example, in the USA a first phase clinical trial has been applied on 45 healthy adult volunteers, with two shots 28 days apart [6,7]. The washing of hands with soap and water for $20 \mathrm{sec}-$ onds; use of surface disinfectants with alcohol and sanitizer; social/physical distancing; isolation/staying home; quarantine; careful disposal of infected materials and nasal secretions are the most effective prevention and control methods to combat the disease [6]. This review was aimed at describing and reviewing the global public health significance, community and healthcare perception, treatments, prevention and control methods related to the COVID-19 Outbreak.

\section{Methods}

In this review, the literature has been searched by following online databases, including MedRxiv, Pubmed, MEDLINE and Google scholar databases. Key search terms used were: 'COVID-19', '2019 Novel coronavirus', '2019-nCoV', 'Novel coronavirus'and 'Pneumonia' to search the literature. Scientific papers published online by the Center for Disease Control (CDC) and the World Health Organization in the English language from 1 January to 6 May 2020 were included in this analysis.

\subsection{Data collection and analysis}

The articles were screened independently by two reviewers for eligibility. A third reviewer was consulted to resolve disagreements. The reviewers independently reviewed the titles, authors, year of publication and abstracts against eligibility criteria. 
Table 1

Public Health Significances of Coronavirus Disease 2019 (COVID-19)

\begin{tabular}{|c|c|c|}
\hline S.No & Public Health Significances from Relevant Literature & $\begin{array}{l}\text { Authors and Published } \\
\text { Year }\end{array}$ \\
\hline 1 & $\begin{array}{l}\text { COVID-19 has affected older people who may also be experiencing further distress related to psychiatric } \\
\text { conditions. }\end{array}$ & Lima et al. [9] \\
\hline 2 & $\begin{array}{l}\text { National readiness capacities are critically important to understand how to identify and slow COVID-19 } \\
\text { transmission using local risk assessment. }\end{array}$ & Kandel et al. [6] \\
\hline 3 & $\begin{array}{l}\text { There was a lack of adequate knowledge among health professionals as regards COVID-19 and its overall } \\
\text { pathological characteristics. }\end{array}$ & Wang et al. [9] \\
\hline 4 & A number of patients and front-line health workers have been prone to COVID-19 & Lima et al. [7] \\
\hline 5 & $\begin{array}{l}\text { The transmission of the Novel } 2019 \text { Coronaviruses(COVID-19) pandemic disease outbreak has been } \\
\text { rapid from country to country. }\end{array}$ & Ren et al. [8] \\
\hline 6 & The morbidity and mortality related to COVID-19 are very high. & Lai et al. [23] \\
\hline 7 & The estimated rate of case fatality has icreased from 2 to $3 \%$. & Singhal. [10] \\
\hline 8 & $\begin{array}{l}\text { The prevalence of comorbidities in the Novel } 2019 \text { Coronavirus (COVID-19) pandemic disease outbreak } \\
\text { in Wuhan has increased. }\end{array}$ & Yang et al. [11] \\
\hline 9 & $\begin{array}{l}\text { Quarantine is the most important alternative solution to slow the transmission of COVIDF-19 across the } \\
\text { world, for example, during quarantine of the cruise ship Yokohama, in Japan, the initial investigation of } \\
\text { transmission of COVID-19 was seen among crew members in February } 2020 \text {. }\end{array}$ & Kensaku et al. [14] \\
\hline 10 & $\begin{array}{l}\text { Exceptionally, the clinical features of the COVID-19 panademic disease outbreak are related to } \\
\text { pneumonia and were easy transmitted to other pneumonias (changed). }\end{array}$ & Kensaku et al. [14] \\
\hline 11 & $\begin{array}{l}\text { Another prevention and control method to combat the Novel } 2019 \text { Coronavirus (COVID-19) is isolation. } \\
\text { It helps to separate suspected or confiremed cases; for instance, the first coronavirus case was seen with } \\
\text { the pneumonic case of a male patient in Saudi Arabia. }\end{array}$ & Zaki et al. [13] \\
\hline 12 & $\begin{array}{l}\text { Most researchers have assessed the epidemiological and clinical nature of COVID-19. For example, one } \\
\text { of the research findings showed that in the first instance, about } 99 \text { cases of the } 2019 \text { novel coronavirus } \\
\text { pneumonia was confirmed in Wuhan, China. }\end{array}$ & Chen et al. [15] \\
\hline 13 & $\begin{array}{l}\text { Currently, severe pneumonia has been most commonly seen among } 10 \text { neonates born to mothers with } \\
\text { 2019- nCoV using a clinical analysis. }\end{array}$ & Zhu et al. [16] \\
\hline 14 & Infected pneumonia is one of the early transmission dynamics of 2019 coronavirus disease in worldwide. & Li et al. [30] \\
\hline 15 & $\begin{array}{l}\text { Pregnant women are susceptible to COVID-19 and are more likely to have complications and even } \\
\text { progress to severe illness. }\end{array}$ & Shaoshuai et al. [17] \\
\hline 16 & $\begin{array}{l}\text { There is some variation among the three consecutive coronavirus diseases; therefore, the detection of } \\
\text { SARS-CoV-2 in different types of clinical specimens. }\end{array}$ & Wenjie [21] \\
\hline 17 & $\begin{array}{l}\text { Evidence has shown that the clinical characteristics of } 138 \text { hospitalized patients with } 2019 \text { novel } \\
\text { coronavirus were due to infected pneumonia in Wuhan, China. }\end{array}$ & Wang et al. [22] \\
\hline 18 & The majority of COVID-19 transmission is from person-to-person. & Jasper et al. [20] \\
\hline 19 & $\begin{array}{l}\text { Clusters of severe respiratory illness similar to sever acute respiratory syndrome Coronavirus are caused } \\
\text { by the current } 2019 \text { Novel Corona virus(2019-nCoV infection). Moreover, it is associated with Intensive } \\
\text { Care Unit (ICU) admission and high mortality. }\end{array}$ & Chaolin et al. [19] \\
\hline
\end{tabular}

\section{Results}

The current systematic review assesses the public health significance from the key relevant literature, various perceptions of COVID-19, treatments and prevention and control methods implemented to slow its transmission. A psychiatric situation directly related to distress has accompanied the COVID-19 disease outbreak, and has particularly affected the elderly section of the population, $>65$ years old and older (Table 1). Moreover, the clinical problems of the severe stages of COVID-19, such as pneumonia and its transmission to other pneumonias, have increased from time to time in various nations around the world. Many of those patients affected and front line health workers are highly prone to these infections [7].

The findings also indicated that the virus spread rapidly from one country to many other countries around the world [10]; therefore, national readiness capacities are necessary to slow COVID-19 transmission using the vital tools of local risk assessment to understand how the government, managers, healthcare providers, prevention and control awareness committees, policy makers, community leaders, and all other stakeholders including and community at large can contribute to slowing the transmission of the virus in various countries worldwide. Hence, this support may help communities to implement life-saving actions [6,9]. Evidence showed that most health professionals did not have adequate awareness concerning the pathological features of COVID-19 [9].

The prevalence of COVID-19 in Wuhan, Hubei city, China was very high, and the case fatality rate was also estimated to range from 2 to $3 \%$ [10,11]. Even though the virus was observed as a minor problem from the 
Table 2

Perspectives on Coronavirus Disease 2019 (COVID-19)

\begin{tabular}{|c|c|c|}
\hline S.No & Communities' Perspectives on Coronavirus Disease 2019 & $\begin{array}{l}\text { Authors and } \\
\text { Published Year }\end{array}$ \\
\hline 1 & $\begin{array}{l}\text { The three most important public health problems of SARS, MERS and COVID-19 were observed in the } \\
\text { autopsies. }\end{array}$ & Wang et al. [9] \\
\hline 2 & $\begin{array}{l}\text { Almost all countries in the world are using analysed data at a regional level from six geographical WHO } \\
\text { regions. }\end{array}$ & Kandel et al. [6] \\
\hline 3 & The causative agents and emotional impact of COVID-19 has been identified using a situational framework. & Lima et al. [7] \\
\hline 4 & $\begin{array}{l}\text { Many of the research findings have revealed that confirmed diagnosis of COVID-19 must be supported by } \\
\text { epidemic history, disease onset charcterstics, serological and pathogenic microorganisms test. }\end{array}$ & Rent et al. [8] \\
\hline 5 & $\begin{array}{l}\text { One of the most important perspectives on Coronavirus Disease } 2019 \text { derives from the daily cumulative } \\
\text { index (DCI). }\end{array}$ & Lai et al. [23] \\
\hline 6 & $\begin{array}{l}\text { Special molecular tests have been used to demonstrate the presence of the Corona virus (COVID-19) in } \\
\text { respiratory secreations. }\end{array}$ & Singhal. [10] \\
\hline 7 & $\begin{array}{l}\text { The computerized tomoghraphic chest scan is usually abnormal even in those with no sysmptoms or mild } \\
\text { diseases. }\end{array}$ & Singhal. [10] \\
\hline 8 & Common laboratory findings include normal/low white cell count with elevated C-reactive protein(CRP). & Singhal. [10] \\
\hline
\end{tabular}

perspectives of mortality or disease burden, the outbreak reminded the world of its shared vulnerability to a pandemic infection. For instance, the clinical characteristics of the 138 hospitalized patients with confirmed COVID-19 who were also infected with pneumonia [12]. It also highlighted the weakened state of essential public-health emergency services, not only in Wuhan, China, but also in a total of 212 countries worldwide.

The isolation of COVID-19 from a man with pneumonia in Saudi Arabia was observed in 2020 [13]. Similarly, there was an initial investigation of the transmission of COVID-19 among crew members on the cruise ship Yokohama in Japan in February 2020 [14]. together with the epidemiological and clinical nature of 99 cases of pneumonia due to COVID-19 recorded as epidemic disease in Wuhan city, China [15]. Specifically, the epidemiological and clinical analysis of about 10 neonates born to mothers with the disease indicated severe pneumonia [16]. The research findings suggested that pregnant women are more susceptible to COVID19 and are more likely to have complications and even progress to severe illness due to the disease [17]. The early transmission dynamics of this disease appear to be similar to those of infective pneumonia [18]. Meanwhile, most of the countries followed the quarantine rules as one of the critically important prevention and control methods to deal with the COVID-19 disease outbreak.

Most of the studies reviewed showed that Coronavirus infection caused groups of severe respiratory illness similar to severe acute respiratory syndrome (SARS) corona virus, and was associated with Intensive Care Unit (ICU) admission and high morbidity and mortality rates [19]. Meanwhile, the route of transmis- sion is person-to-person [20]. With regard to the basic method of identifying COVID-19, the WHO have used various types of clinical specimens to identify the cause of the disease [21].

The study results shown in Table 2 indicate different perceptions and sensations among the communities and healthcare providers as regards COVID-19. Some of the researchers addressed the variation of pathological characteristics of COVID-19, and they have reported on the effect of autopsies of the aforementioned previous SARS, MERS and COVID-19. The pathologic nature of those three consecutive Coronavirus outbreaks has been observed through various methods of investigation and isolation systems [22].

The six geographical WHO regions have employed various types of data analysis according to their regional contexts. This may be supported to identify the regional problems related to COVID-19 [6,22]. Most of the research findings, for example, of Lima and his colleagues (2020) indicated that many high, low and middle-income countries have identified the etiology and psychological factors and more of the emotional impacts of COVID-19 using a situational framework [7,22]. In order to confirm COVID-19 cases, most of the healthcare settings analyzed the epidemic nature of the virus, onset and overall characteristics of the disease outbreak, including serology and pathogenicmicrobe test results to identify the type of virus that caused the COVID-19 outbreak [8]. In other words, some of the laboratory experts used the daily cumulative index of COVID-19 [23]. Moreover, special molecular tests were used to demonstrate the presence of the SARS-nCoV-2 virus which caused the COVID-19 outbreak in the respiratory secretions, accompanied by a computerized tomographic chest scan. As a result, they 
Table 3

Treatment trial of Coronavirus Disease 2019 (COVID-19)

\begin{tabular}{|c|c|c|}
\hline S.No & Treatments of Coronavirus Disease 2019 & $\begin{array}{l}\text { Authors and } \\
\text { Published Year }\end{array}$ \\
\hline 1 & $\begin{array}{l}\text { From the beginning of the first confirmed COVID-19 pandemic disease outbreak, Kaletra and traditional } \\
\text { Chinese medicine has played an important role in the treatment of viral pneumonia. }\end{array}$ & Wan et al. [24] \\
\hline 2 & $\begin{array}{l}\text { In order to allow the day to day operational activities at various hospitals, most of the facilities used blood } \\
\text { direct from blood banks in non-affected areas of the community to keep their blood stocks stable. }\end{array}$ & Pagano et al. [25] \\
\hline 3 & $\begin{array}{l}\text { Essential supportive therapies are practiced for COVID-19; however, they have not effectively manged the } \\
\text { causative agent of cases. }\end{array}$ & Singhal $[10]$ \\
\hline 4 & The value of any antiviral agents is yet to be established. & Singhal [10] \\
\hline 5 & $\begin{array}{l}\text { COVID-19-associated pneumonia has been treated with chloroquine phosphate; drug which has apparently } \\
\text { shown some efficacy in treatment. }\end{array}$ & Gao [27] \\
\hline 6 & $\begin{array}{l}\text { Scientists are currently trying to discover whether a number of modern and traditional drugs may be useful } \\
\text { in treating the coronavirus (COVID-19) pandemic disease outbreak. }\end{array}$ & Dong [28] \\
\hline 7 & Intitialy, antiviral treatments are used as supportive theraphy for COVID- 19. & Şimşek Yavuz [29] \\
\hline 8 & $\begin{array}{l}\text { Many researchers have conducted various clinical, observational and management studies of COVID-19 } \\
\text { patients. }\end{array}$ & Li [30] \\
\hline 9 & $\begin{array}{l}\text { There is advocacy for prospective clinical trials to test the post-exposure potential of hydroxychloroquine } \\
\text { against COVID-19 if implemented and used appropriately. }\end{array}$ & Picot et al. [31] \\
\hline 10 & $\begin{array}{l}\text { Chloroquine and hydroxychloroquine are the drugs most commonly used to prevent and treat novel } \\
\text { coronavirus disease (COVID-19) in Africa. }\end{array}$ & Abena et al. [32] \\
\hline
\end{tabular}

saw abnormal results in the patients with confirmed COVID-19, as well as in those with no symptoms or with mild indications as such fever, coughing, sneezing and a runny nose. Hence, most of the laboratory centers followed various types of investigation and evaluation methods to identify the causative agents for COVID-19 then, after their active diagnostic evaluations, employed common laboratory test result such as might indicate whether the level of white blood cells was normal, abnormal or low and other C-reactive protein (CRP) was elevated [10,23].

Table 3 indicates that no specific vaccine or treatment for COVID-19 has been found for use during the outbreak, however, most countries have used various existing supportive treatments to slow the transmission of COVID-19 from person to person, such as isolation and quarantine techniques. For example, Kaletra and traditional Chinese medicine have played a key role as essential supportive therapies in the treatment of the viral pneumonia [10] and minimized viral load [24]. Meanwhile, blood transfusion using normal volumes of blood units was provided by the blood banks of nonaffected areas of the community to keep inventory stable and allow for routine hospital operations [25]. In other words, the main roles of antiviral drugs are still being established in various nations [10].

The results also show that chloroquine phosphate is one of the most important drugs for supportive treatment, and is apparently highly efficacious in the treatment of COVID-19 cases associated with mild and severe pneumonia [26,27]. However, some scientists have been working to discover drugs to manage Coronavirus infection [28]. Even though there is no specific treatment for COVID-19, antiviral treatments have been tried in almost all countries as a way to decrease morbidity and mortality rates [29].

Currently, the main scientific surveillance and administration bodies for supportive drugs for COVID19 patients are investigating the use of hydroxychloroquine $[30,31]$. Drugs like chloroquine and hydroxychloroquine have been the ones most used for the prevention and control of COVID-19 transmission and have apparently effectively treated the novel COVID-19 outbreak in the Africa region [32].

The results in Table 4 show that the slowing of COVID-19 transmission can be efficiently effected by the implementation of various methods of prevention and control. These include slowing transmission by means such as community and healthcare awareness, restriction of movement from place to place, allowing only local travel or restricting all travel [23], monitoring the spread of COVID-19, increasing distribution of safety materials (face masks, gloves) for all communities and particularly for physicians. Meanwhile, one of the most important and easiest way of decreasing Coronavirus cross contamination is the frequent washing of hands using soap and water and the use of sanitizers [1]. Furthermore, both quarantine and severe contagion diseases control techniques in any health settings that include contact and droplet protection, as well as the avoidance of a high degree of stress and emotional disturbance, as well as adequate sleep, a balanced diet and the avoidance of restricted food related to COVID19 and related complications $[1,10]$. 
Table 4

Prevention and control methods for COVID-19

\begin{tabular}{|c|c|c|}
\hline S.No & Prevention and Control Methods & $\begin{array}{l}\text { Authors and } \\
\text { Published Year }\end{array}$ \\
\hline 1 & Restricting travel & Lai et al. [23] \\
\hline 2 & Controlling the distribution of Masks & \\
\hline 3 & Extensive monitoring of spread of COVID-19 & \\
\hline 4 & Giving valuable information and educating people & \\
\hline 5 & Frequent washing of hands with soap and water or use of alcohol-based hand rub & $\begin{array}{l}\text { World Health } \\
\text { Organization [1] }\end{array}$ \\
\hline 6 & $\begin{array}{l}\text { Covering mouth and nose with flexed elbow or tissue when coughing or sneezing - throw tissue away } \\
\text { immediately and wash hands }\end{array}$ & \\
\hline 7 & Avoiding close contact with anyone that has symptoms such as fever or cough & \\
\hline 8 & $\begin{array}{l}\text { Quarantine, avoiding stress, engaging in healthy activities such as regular exercise and adequate sleep, } \\
\text { eating healthy food and keeping things in perspective }\end{array}$ & $\begin{array}{l}\text { World Health } \\
\text { Organization [1] }\end{array}$ \\
\hline 9 & Home isolation of suspected cases and those with mild illness & Singhal. [10] \\
\hline 10 & Strict infection control measures in at hospitals, including contact and droplet precautions. & Singhal. [10] \\
\hline
\end{tabular}

\section{Discussion}

The results of this study showed that older age groups are highly vulnerable to COVID-19, followed by children and other age groups. They indicated that the morbidity and mortality numbers vary depending on age and from country to country. The findings are supported by the 2020 report from the European Centre for Disease Prevention and Control, which found that the number of confirmed and hospitalized COVID-19 patients with severe clinical symptoms accounted for $15 \%$ of the total; however, the total number of deaths were $12 \%$. The number of deaths in Germany, Italy and Spain increased rapidly, and there the case fatality among older people is also increasing [33]. As with this study, the older age groups were found to be dying at a rate greater than all other age group in every country; however, there was a very large variation in death and age from country to country $[23,38,39]$. This is an indication that it may offer a way to analyze the current disease outbreak and community health gaps between countries in the main working age groups. The probability of dying in adulthood is greater than in other age groups in almost all countries, but the variation in death rate related to age between countries is very large.

This review revealed a lack of global policy, strategic plans, and a general national readiness to slow COVID-19 transmission. Similarly, a study conducted in USA [36] described the way in which initial public health emergency response and clinical guidance was being applied in anticipation of further COVID-19 cases in that country, but that this could not efficiently and effectively prevent the ultimate occurrence of continued, widespread transmission of COVID-19. The WHO has advised the implementation of a five stage strategy to slow the spread of mild and severe symptoms of the disease [36] but fundamental questions have been raised by many communities regarding the necessity of taking the preventive and control measures advised to slow the outbreak is too high. The report [37] found that the challenges of COVID-19 and its impact on the community continues to grow. Moreover, many of the world's nations are facing unprecedented problems with the number of cases [37]. Evidence showed that the public health emergency measures that are a routine preventive action against the spread of the Coronavirus (COVID-19) pandemic include: staying at home if you feel unwell, covering the mouth and nose with a flexed elbow or tissue when coughing or sneezing, disposing of used tissues immediately, washing hands often with soap and water and regularly cleaning frequently touched surfaces and objects [38].

The results of the study showed that there is still inadequate awareness among communities and healthcare providers as to how to combat COVID-19. Healthcare providers play a key role in providing relevant information about the distribution of confirmed COVID-19 cases, deaths and recovery and/or discharge of patients from temporary management centers, hospitals and waiting areas, and on how well transmission of COVID19 is being slowed from person to person and from country to country. It also indicated the ways of avoiding risk among the communities. A study conducted in Kenya [39] suggested that the healthcare-provider workforce was intensified in sub-Saharan Africa, including Ethiopia, months ago. A report from the National Nurses Union in the USA indicated that only one-third of its members in various healthcare organizations had sufficient stocks of personal protective equipment (PPE) to respond adequately to the COVID19 outbreak. Similarly, there are reports of a lack of awareness among many of the healthcare providers in 
some hospitals in France and Italy. Evidence also suggests that many healthcare providers have run out of masks, forcing doctors to examine and treat confirmed COVID-19 patients without adequate protection [39].

This study found that the prevalence of COVID-19 is very high, and that there has been a slight increase in fatality in the cases in China, as well as in all other countries. Moreover, despite the status level of the outbreak of COVID-19 being changed from epidemic to pandemic, there was weak application of prevention and control methods and many governments were slow in recognizing the pandemic as a public health emergency and acting to slow the spread of COVID-19. The isolation of COVID-19 patients from groups with pneumonia would have helped to identify the confirmed COVID-19 case, and how the community applied the efficient and effective quarantine to slow COVID-19 transmission from person to person. Most of the time, pregnant women are highly vulnerable to COVID-19 and are more likely to have mild to severe complications or even progress to severe illness in a disease outbreak such as COVID-19; SARS-CoV-2.

This study findings showed that there was a wide variation of pathological characteristics among SARS, MERS and COVID-19 diseases outbreak. COVID-19 in particular has killed many people with mild and severe symptoms if they were not able to access healthcare providers at the onset of their cases. Moreover, there was some variation in community and healthcare providers' perception of how best to slow COVID-19 transmission.

This study result showed that most developed and developing countries have identified the impact of COVID-19. For example, the emotional impact has critically aggravated the severity of COVID-19 across all countries. As a result, there have been increasing etiology and psychological factors related to COVID-19 diseases outbreak in communities. Even though the healthcare settings were strongly assessed, the epidemic characteristics of COVID-19, including serology and pathogenic microbes test, there were abnormal results of patients confirmed as COVID-19 cases, as well as those with no symptoms or mild effects such as fever, coughing, sneezing and runny nose.

The results of this study revealed that there is a lack of direct therapeutic management available against SARS-CoV-2. Nonetheless, most countries started using some of the supportive drugs used in the treatment of HIV/AIDS, such as anti retro-virals (ART), and antimalarial drugs like chloroquine, as well as blood transfusion, in an attempt to manage the COVID-19 outbreak associated with pneumonia. Some countries, including China, used essential supportive therapies as such Kaletra and traditional Chinese medicines normally used to treat many viral complications such as pneumonia. In a similar study conducted in Italy [40], it was found that most of the drugs used against COVID-19 have not been endorsed for the purpose by scientists, or were in immature stages of development; nevertheless, a combination of anti-viral drugs and supportive care has been used to slow the progress of disease in COVID-19 [40].

\section{Conclusions}

The risk of a COVID-19 outbreak was very high in countries worldwide. Morbidity and mortality rates have increased in more than 200 countries. It is clear that COVID-19 outbreak limits, public health emergency targets and health policy instruments for the prevention and control of this disease have often been used to slow its transmission. In particular, governments should be implementing serious health policies to prevent and control the spread of COVID-19, and a high degree of attention to prevention and control actions should be paid around the world. It is important to ensure that the intended protection and prevention of the disease outbreak are achieved, and that any further protection and control methods are taken without delay. As a result, the research team recommends the implementation of continuous surveillance, investigation, human exposure assessment, WHO standard guidelines and rules and regulation upon the prevention and control methods of COVID-19. The results of the study identified the seriousness of COVID-19 for pregnant mothers and infants, and how the disease is transmitted from person to person. Therefore, the expansion of the public health emergency for the prevention and control of COVID-19, and the system for dealing with emergency disease outbreaks and the provision of new emergency medical services and public health emergency preparedness have naturally led to the current problems as regards the quality of healthcare delivery systems provided, and the ability of the public-health emergency systems to handle the WHO standard COVID-19 prevention and control methods in each country. Awareness creation in the community and further applied research on effective vaccines and treatment should be done. Moreover, epidemiological surveys should be implemented to manage the ongoing risk of outbreaks of COVID-19 and other endemic, epidemic, pandemic and sporadic disease outbreaks in various countries and continents. 


\section{Authors' contributions}

AAG designed the review protocol. Both AAG and TB designed the search strategy for this systematic review protocol and performed the search in collaboration with online healthcare librarians. AAG, TB, EW, AFA,SM, HZA, AK, BAT, BAA, BSD, NSZ, AGG, $\mathrm{BM}$, and QKY have participated in data selection, data extraction, data analysis, and interpretation of the results. All authors critically revised, read, and approved the final manuscript.

\section{Acknowledgments}

The authors would like to thank Salale University, and all those individuals who helped with the review are also warmly acknowledged.

\section{References}

[1] World Health Organization, Director-General's remarks at the media briefing on $2019-\mathrm{nCoV}$ on 11 February (2020). https://www.who.int/dg/speeches/detail/who-directorgeneral-s-remarks-at-the-media-briefing-on-2019-nCov-on11-February-2020 [Accessed on February 12, 2020].

[2] J. Xu, Y. Chen, H. Chen and B. Cuo, 2019 Novel Coronavirus outbreak, a quiz and final exam? Front Med (2020). doi: 10.1007/S11684.020-0753-1.

[3] N. Chen, M. Zhou and X. Dong et al., Epidemiological and clinical characteristics of 99 cases of 2019 novel coronavirus pneumonia in Wuhan, China: A descriptive study, Lancet 395 (2020), 507-513. doi: 10.1016/S0140-6736(20)30211-7.

[4] Centers for diseases control and prevention, Coronavirus Diseases 2019 (COVID-19). CDC24/7: Saving Lives, Protecting people, CDC.Gov, (2020).

[5] National Institutess of Health, NHI clinical trial of Investigational Vaccine for COVID-19 begins, http://www/nih.gov.2020 [Accessed on May, 07, 2020].

[6] N. Kandel, S. Chungoing, A. Omaar and J. Xing, Health security capacities in the context of COVID-19 out break: An Analaysis of International Regulations annual report data from 182 countries, Lancet (2020). S0140-6736:30553-5.

[7] C.K.T. Lima, F.M.M. Carvalho, I.A.A.S. Lima, J.V.A.O. Nunes, J.S. Saraiva, R.I. Deseuzu, C.G.L. de Silva and M.R. Neto, The emotional impact of coronavirus 2019-nCoV (new coronavirus diseases), Psychatric Res 12(287) (2020), 112915.

[8] Y.H. Ren, S.Y. Wang, M. Eu, Y.M. Guo and H.P. Dai, [When COVID-19 encounters Interstitial Lung diseases]: Challenges and management, Zhonghua JHE He Hu Za Zhi 43 (2020), E039. doi: 10.3760/Gma.jcn12147-20200315-00339.

[9] H.J. Wang, S.H. Du, X. Yue and C.X. Chen, Review and perspect of pathological features of corona virus diseases, $\mathrm{FaYi}$ Xue Zahi 26(1) (2020), 16-20.

[10] T. Singhal, A review of coronavirus disease-2019 (COVID-19), Indian J Pediatr 87(4) (2020), 281-286. doi: 10.1007/s12098020-03263-6
[11] J. Yang, Y. Zheng, X. Gou, K. Pu, Z. Chen, Q. Guo, R. Ji, H. Wang, Y. Wang and Y. Zhou, Prevalence of comorbidities in the novel Wuhan Coronavirus Disease 2019 (COVID-19) infection: A systematic review and meta-analysis, International Journal of Infectious Diseases (2020). doi: 10.1016/j.ijid.2020. 03.017 .

[12] O. Wang, Y.E. Qiu, J.Y. Li, Z.J. Zhou, C.H. Liao and X.Y. Ge A unique protease cleavage site predicted $\mathrm{ij}$ the sprike protein of the novel pneumonia coronavirus (2019-nCoV) potentially related to viral tramnsmissibly, Virologica Sinica (2020). doi: 10.1007/s12250-020-00212-7.

[13] A.M. Zaki, S. van Boheemen, T.M. Bestebroer, A.D. Osterhaus and R.A. Fouchier, Isolation of a novel coronavirus from a man with pneumonia in Saudi Arabia, The New England Journal of Medicine 367(19) (2012), 1814-1820.

[14] K. Kensaku, K. Hajime, Y. Takuya, M. Tamano, S. Motoi and W. Takaji, Initial investigation of transmission of COVID19 among crew members during quarantine of a cruise shi, Yokohama, Japan, February (2020).

[15] N. Chen, M. Zhou, X. Dong, J. Qu, F. Gong, Y. Han, Y. Qiu, J. Wang, Y. Liu, Y. Wei et al., Epidemiological and clinical characteristics of 99 cases of 2019 novel coronavirus pneumonia in Wuhan, China: A descriptive study, Lancet (2020).

[16] H. Zhu, L. Wang, C. Fang et al., Clinical analysis of 10 neonates born to mothers with 2019-nCoV pneumonia, Transl Pediatr, (2020). doi: 10.21037/tp.2020.02.0.

[17] W. Shaoshuai, G. Lili, C. Ling, L. Weiyong, C. Yong, Z. Jingyi and F. Ling, A case report of neonatal 2019 coronavirus disease in China, Published by Oxford University Press for the Infectious Diseases Society of America, All rights reserved, (2020). doi: 10.1093/cid/ciaa225.

[18] Q. Li, X. Guan, P. Wu, X. Wang, L. Zhou, Y. Tong, R. Ren, K.S.M. Leung, E.H.Y. Lau, J.Y. Wong et al., Early Transmission Dynamics in Wuhan, China, of Novel CoronavirusInfected Pneumonia, The New England Journal of Medicine (2020).

[19] H. Chaolin, W. Yeming, L. Xingwang, R. Lili, Z. Jianping and H. Yi et al., Clinical features of patients infected with 2019 novel coronavirus in Wuhan, China, Published Online (24 January 2020). 30183-30185. doi: 10.1016/S0140-6736(20)2020.

[20] F.W.C. Jasper, Y. Shuofeng, K. Kin-Hang, K.W.T. Kelvin, C. Hin and Y. Jin et al., A familial cluster of pneumonia associated with the 2019 novel coronavirus indicating person-to-person transmission: A study of a family cluster, Published Online (24 January 2020). doi: 10.1016/S0140-6736(20)30154-9.

[21] T. Wenjie, Detection of SARS-CoV-2 in Different Types of Clinical Specimens National Institutefor Viral Disease Control and Prevention, China CDC, 155 Changbai Rd, Changping District, Beijing 102206, China, 2020.

[22] C. Wang, R. Pan, X. Wan, Y. Tan and L. Xu, C.S. HO and R.C. Ho, Immediate psychological responses and associated factors during the initial stage of the 2019 coronavirus diseses (COVID-19) epidemic among the general population in China, Int J Environ Res Public Health 17(5) (2020), Pii: E1729.

[23] C.C. Lai, C.Y. Wang, Y.H. Wang, S.C. Hsueh, W.C. Ko and P.R. Hsueh, Global epidemiology of coronavirus disease 2019: Disease incidence, daily cumulative index, mortality, and their association with country healthcare resources and economic status, Int J Antimicrob Agents 18 (2020), 105946. doi: 10.1016/j.ijantimicag.2020.105946.

[24] S. Wan, Y. Xiang, W. Fang, Y. Zheng, B. Li, C. Lang, D. Huang, X. Sug, J. Lv, L. Shen, H. Yang, G. Huang and R. Yang, Clinical feature and tratement of COVID-19 patients in 
Northeacst Chingqing, J Med Viro, (2020). doi: 10.1002/jmv. 2583.

[25] M.B. Pagano, J.R. Hess, H.C. Tsango, E. Staley, T. Gernsheimer, N. Ser, C. Clark, J. Nester, C. Bailey and K. Alcon, Prepare to adapt: Blood supply and transfusion support during the first 2 weeks of the 2019 novel coronacirus (COVID-19) pandemic affecting Washington state, Transfusion (2020). doi: 10.1111/trf.15789.

[26] K.J. Goh, M.C. Choong, E.H. Cheong, S. Kalimuddin, S. DUUWens, K.S. Phua and S.H. Mihideen, Rapid progression to acute respiratory distress syndrome: Review to current understanding of critical illness-from COVID-19 infection, Ann Acad Med Singapore 49(1) (2020), 1-9.

[27] J. Gao, Z. Tian and X. Yang, Breakthrough, Chloroquine phosphate has shown apparent efficacy in treatment of COVID-19 associated pneumonia in clinical studies, Biosci Trends 14(1) (2020), 72-73. doi: 10.5582/bst.2020.01047.

[28] L. Dong, S. Hu and J. Gao, Discovering drugs to treat coronavirus disease 2019 (COVID-19), Drug Discov Ther 14(1) (2020), 58-60. doi: 10.5582/ddt.2020.01012.

[29] S.Ş. Yavuz, S. Ünal, Antiviral treatment of COVID-19, Turk J Med Sci 50(SI-1), (2020), 611-619, Published 2020 Apr 21. doi: 10.3906/sag-2004-145.

[30] T. Li, H. Lu and W. Zhang, Clinical observation and management of COVID-19 patients, Emerg Microbes Infect 9(1) (2020), 687-690. doi: 10.1080/22221751.2020.1741327.

[31] S. Picot, A. Marty, A.L. Bienvenu et al., Coalition: Advocacy for prospective clinical trials to test the post-exposure potential of hydroxychloroquine against COVID-19, [published online ahead of print, 2020 Apr 4]. One Health, (2020), 100131. doi 10.1016/j.onehlt.2020.100131

[32] P.M. Abena, E.H. Decloedt, E. Bottieau et al., Chloroquine and Hydroxychloroquine for the Prevention or Treatment of Novel Coronavirus Disease (COVID-19) in Africa: Caution for Inappropriate Off-Label Use in Healthcare Settings, [published online ahead of print, 2020 Apr. 22]. Am J Trop Med Hyg, (2020). doi: 10.4269/ajtmh.20-0290.
[33] Instituto Superiore di Sanità, Characteristics of COVID-19 patients dying in Italy Report based on available data on March 20th, (2020), [cited 202023 March]. Available from: https://www.epicentro.iss.it/coronavirus/bollettino/ReportCOVID-2019_20_marzo_eng.pdf.

[34] European Centre for Disease Prevention and Control, Stockholm, Coronavirus disease 2019 (COVID-19) pandemic: Increased transmission in the EU/EEA and the UK seventh update, 25 March 2020. Stockholm: ECDC, (2020).

[35] Geneva Center for Education and Research in Humanitarian action, COVID-19 scientific Resources, Rothschild, Geneva, (2020).

[36] A. Patel, D.B. Jernigian and $2019 \mathrm{nCoV} \mathrm{-} \mathrm{CDC} \mathrm{response}$ team, Initial public Health Response and intiaermin clinical Guideline for the 2019 Novel Coronavirus outbreak-United States, December, 31, 2019, MMWR MOrb Mortal Wkly RCP 69(5) (2020), 140-146.

[37] Open Governement PartnershipCollecting open Goverenment approaches to COVID-19. http://www.Open government partnership, (2020). Org/Collecting-open-government approachesto-covid-19 [Accessed on May, 14, 2020].

[38] UNICEF, World Health Organization and CIFRC, Key message and Actions for COVID-19 prevention and control in Schools, Education in Emergencies, UNICEF New York, (2020).

[39] S. Chatterjee and A. Kagwe, Health Workers are the frontline soliders against COVID-19. Let's protect them, Africa Renewal, Health in Kenya and Siddharth Chatterjee is the United Nations, Kenya, (2020). https://www.un.org/africarenewal/ web-features/coronavirus/health-workers-are-frontlinesoldiers-against-covid-19-let $\%$ E2\%80\%99s-protect-them [Accessed on May, 14, 2020].

[40] C. Perricone, P. Triggiancese, E. Bartoloine, G. Cafaro, A.F Bonifacio, R. Bursi, R. Perricone and R. Gerli, The antiviaral Facet of anti rheumatic dfrugs: Lesson from COVID-19, $J$ Autoimmun, (2020), 102468. doi: 10.1016/j.jaut,2020.102468. 